\title{
Influence of Different Light-curing Units on the Surface Roughness of Restorative Materials. In situ Study
}

\author{
Juliane Cristina Ciccone-Nogueira ${ }^{\mathrm{b} *}$, Wanessa Christine de Souza-Zaronia, \\ Michelle Alexandra Chinelatti, Regina Guenka Palma-Dibb ${ }^{\mathrm{b} *}$ \\ ${ }^{a}$ Universidade Cruzeiro do Sul, São Paulo - SP, Brazil \\ ${ }^{\mathrm{b}} \mathrm{FORP} / \mathrm{USP}$ Depto de Odontologia Restauradora, Av. do Café, s/n, \\ 14040-900 Ribeirão Preto - SP, Brasil
}

Received: November 30, 2006; Revised: September 3, 2007

\begin{abstract}
The aim of this study was to evaluate the influence of different light sources (LED and Halogen lamp) on the roughness (superficial) of composite resin (Filtek Z250, Filtek P60, Charisma and Durafill) varying postirradiation times, in an in situ experiment. For this purpose, 80 specimens were made in polyurethane moulds. Ten volunteers without medicament use and good oral condition were selected and from them study moulds were obtained. A palatal intra-oral acrylic resin appliance was made for each of the subjects of the experiment. In each appliance, two specimens of each material were fixed (LED/Halogen lamp - control group). Roughness tests were performed immediately and 30 days after initial light-curing. Statistical analysis was performed using ANOVA. Statistically significant difference was observed only between post-irradiation times, where the $30^{\text {th }}$ day showed the highest roughness values. It be concluded that roughness was influenced only by post-irradiation times, presenting the 30 - days period inferior behavior.
\end{abstract}

Keywords: roughness, composite resin, light sources

\section{Introduction}

Resin composites have been widely used in daily clinical practice because of their esthetic advantages, improved bonding to tooth structure and enhanced mechanical properties. However, these materials still have several shortcomings, such as polymerization shrinkage, incomplete conversion of monomers in polymers, and water uptake upon exposure to the oral environment ${ }^{1}$, which can provide its mechanical properties reduction. The conversion of monomers in polymers is associated to the degree of polymerization of the composite, which has been related to several factors ${ }^{2,3}$, including resin composition $^{4,5}$ and light sources characteristics ${ }^{6-10}$.

In this context, halogen bulb-based light-curing units are the systems most commonly used in dentistry for cured dental composites $^{11,12}$, whereas the light is able to activate the camphoroquinone photoiniciator for the polymerization reaction ${ }^{13}$. This appliance, if correctly employed, allows adequate conversion of composite and the achievement of desired mechanical properties. However, the search for a lesser exposure time, the possibility of higher distance between curing tip and restoration, and increased lifetime of appliance, lead to the development of recent technologies, such as LED, Plasma Arc Curing and Xenon Lamp.

LED uses a solid-state semiconductor (diode) that converts electrical energy directly into blue light ${ }^{14,10}$. One of the major advantages of this system, which incentives its use in dental practice, is related to the increased lifetime of this appliance, in such case, their performance does not significantly reduce with time ${ }^{14}$ (not occur the significantly reduction in the potency of the appliance). This characteristic is very important because an unsuitable potency can provoke a negative effect on the physical properties of composites and increased risk of premature failure of restorations ${ }^{8}$.

With the introduction of this recent appliance, the development of new studies is need to establish the influence of these light-curing sources in the properties of composite resin, including microhardness, adhesion, polymerization shrinkage and wear resistance. These studies are needed because the longevity of restorative material is associated the mechanical properties obtained after polymerization.

Thus, experiments that evaluate the wear resistance ${ }^{15,16}$ is very important for the success of the restorative treatment, whereas this properties can provide the increase of surface roughness ${ }^{17,18}$, which can promote plaque accumulation, gingival irritation, poor esthetics and color changes, as well as, recurrent decay ${ }^{19,20}$. In the context, the wear resistance can be evaluated through mass loss and superficial smothness ${ }^{18}$ of the material.

However, in vitro studies alone are not able to establish the real properties of the materials, because they not effectively reflect what actually occur in the oral environment. In an attempt to overcome such difficulty, in situ experiments ${ }^{21}$ have been employed, whereas these models function how a bridge between the laboratories studies and clinical trials ${ }^{22}$. Thus, the aim of this study was to evaluate the influence of different light sources on the surface roughness of resin composites exposed to oral environment.

\section{Material and Methods}

This study was approved (Process 2002.1.880.58.6) by Ribeirão Preto School of Dentistry's Ethics Committee, University of São Paulo, Brazil.

For the accomplishment of the study, two light-curing units (Table 1), and four composite resins Filtek Z250, Filtek P60, Charisma and Durafill (Table 2) were employed. For the materials, shade $\mathrm{C}_{2}$ was used intending the color standardization of the experiment.

Initially, ten volunteers, which were not on medication and presenting a good oral condition ${ }^{23}$ (without signal of caries and 
periodontal diseases), were selected. The group consisted of 2 males and 8 females, graduate or post-graduate students of Ribeirão Preto School of Dentistry - University of São Paulo, Brazil. The volunteers were informed about the possible risks involved and his participation was only after providing written formal consent.

Superior dental arch impressions of each volunteer were made with alginate (Jeltrate ${ }^{\circledR}$, Dentisply Industria e Comércio Ltda. Petrópolis/RJ - Brazil, 25660-004) and stone cast moulds (Herostone, Vigodent S. A. Indústria e Comércio - Rio de Janeiro/RJ - Brazil, 21041-150) were obtained. A removable palatal intraoral appliance was manufactured in acrylic resin (Orto-Clas, Clássico Indústria Brasileira -São Paulo/SP - Brazil, 05458-002). In each intraoral appliance, 8 cavities were made $(5 \mathrm{~mm}$ in diameter and $2 \mathrm{~mm}$ in height), being 4 in each side of the appliance, where the specimens of composite resins were fixed with wax (KOTA Indústria e Comércio Ltda. - São Paulo/SP - Brazil, 05572-000).

For the roughness test 80 samples were made, being 20 from each material and 10 from each light-curing unit. The specimens were manufactured using a split bisected cylindrical polyurethane matrix with internal dimensions of $2 \mathrm{~mm}$ in height and $3 \mathrm{~mm}$ in diameter. Composite resin was inserted into the matrix in bulk placements and covered with a polyester strip. A microscope glass slide $(1 \mathrm{~mm}$ thick) was placed on it. The materials were pressed with a load of $500 \mathrm{~g}$ for 30 seconds to remove the material excess, permitting to standardize the thickness of the specimens $(2 \mathrm{~mm})$ and to obtain a parallel and flat surface.

After load removing, the top surfaces of the specimens were light cured for 40 seconds using light-curing units (halogen lamp or LED) at a distance of $1 \mathrm{~mm}$ from the curing tip to the specimens. After three specimens preparation, the light intensity was monitored using a radiometer (Newdent ${ }^{\circledR}$, Ribeirão Preto/SP - Brazil, 14030-140).

The roughness of the materials was evaluated in $\mathrm{Ra}(\mu \mathrm{m})$ using a roughness meter (Prazis, ARO S. A., Buenos Aires, República Argentina) equipped with a $2 \mu \mathrm{m}$ radius diamond stylus, which traversed the surface at a constant speed of $0.05 \mathrm{~mm} / \mathrm{s}$ with a force of $0.7 \mathrm{mN}$. For this purpose, each specimen was carefully fixed with wax on a metallic support and the needle situated at the extremity of the equipment's arm was positioned on the sample surface. The scans were $1.5 \mathrm{~mm}$ in length, and the data were filtered with a cutoff of $0.08 \mathrm{~mm}$. Two additional measurements were accomplished by rotating the disk in an angle of 90 degrees, and a mean value was obtained from the three measurements ${ }^{17}$.
The volunteers were instructed on using and cleaning of the removal palatal intraoral appliance. This plate would be used all day long, during 30 days, and could only be removed during meal and oral hygiene times, when they were wrapped in humid cotton in a closed recipient. Toothbrushes (Bitufo ${ }^{\circledR}$, Montagem e Comércio de Escovas Ltda, Jundiaí/SP - Brazil, 13206-770) and toothpastes (Colgate - Palmolive Industria e comércio Ltda, São Bernardo do Campo/SP - Brazil, 09696-000) were given to the volunteers and they were instructed to clean the plate three times a day. The specimens were brushed with 10 back and forward movements with the toothbrush and toothpaste, while handing the appliance.

The first roughness measurement was performed after composite light curing. Then, the specimens were randomly placed in the oral appliance and utilized by volunteers as previously cited. After 30 days, the specimens were removed from the appliance and roughness measurements were accomplished again.

Data obtained were submitted to the analysis of variance (ANOVA), considering the factors restorative materials, light-curing units and post-irradiation time.

\section{Results}

Statistical analysis did not show significant differences for the resin composite factor (Charisma, Durafill, Filtek P60 and Filtek Z250) and light-curing units (halogen lamp and LED). Conversely, for the post-irradiation time factor (immediately and 30 days), it was observed significant difference, with 30 -days period demonstrating the highest means of roughness (Table 3 ).

\section{Discussion}

The longevity of restorative treatment with resin composites depends on the suitable polymerization of the material, which is directly associated to their mechanical properties, including wear resistance ${ }^{16}$. This property can be evaluated through its mass loss and superficial smoothness ${ }^{18}$ after a certain period. Wear can be defined as the progressive loss of substance, resulted from mechanical interaction between two contacting surfaces, which are in relative motion $^{24}$, providing the dislodgement of filler particles ${ }^{25}$, and the wear of the filler itself. Many variables can influence the extent at which resin composites wears, including filler type and size, as well as, the coupling between filler and resin matrix ${ }^{26}$

However, in vitro studies can be complemented with in situ experiment ${ }^{10,21,24,27}$, whereas this model is performed in the human

Table 1. Light-curing units tested.

\begin{tabular}{|c|c|c|c|}
\hline Light-curing units & Wavelength & Type & Intensity \\
\hline XL $3000-3 \mathrm{M}$ & Approximately $500 \mathrm{~nm}$ & Halogen lamp & $480-530 \mathrm{~mW} \cdot \mathrm{cm}^{-2}$ (40 seconds) \\
\hline Ultraled - DABI ATLANTE & Approximately $480 \mathrm{~nm}$ & LED & $130 \mathrm{~mW} \cdot \mathrm{cm}^{-2}$ (40 seconds) \\
\hline
\end{tabular}

Table 2. Composite resins employed.

\begin{tabular}{cccc}
\hline Material & Composition & Percentagem/Particle size & Manufacturer/Batch no. \\
\hline \multirow{2}{*}{ Z250 } & Zirconium/Silica, BIS-GMA, UDMA e & $60 \%$ volume & $3 \mathrm{M}$ do Brazil \\
& BIS-EMA & $(0.19-3.3 \mu \mathrm{m})$ & $2 \mathrm{MK}$ \\
P60 & Zirconium/Silica, BIS-GMA, UDMA e & $61.7 \%$ volume & $3 \mathrm{M}$ do Brazil \\
& BIS-EMA & $(0.19-3.3 \mu \mathrm{m})$ & $9 \mathrm{AR}$ \\
Charisma & BIS-GMA, bariumaluminofluoridate glass & $36 \%$ volume & $(0.02-2 \mu \mathrm{m})$ \\
& & prepolymerized fragments of & Heraeus Kulzer, Germany \\
Durafill & UDMA, silicon dioxide, prepolymerized & $10-20 \mu \mathrm{m}$ & 060039 \\
& fragments & & 020127 \\
\hline
\end{tabular}


Table 3. Mean values and standard deviations of the roughness.

\begin{tabular}{|c|c|c|c|c|c|c|c|c|}
\hline & \multicolumn{2}{|c|}{$\mathrm{Z} 250$} & \multicolumn{2}{|c|}{ P60 } & \multicolumn{2}{|c|}{ Charisma } & \multicolumn{2}{|c|}{ Durafill } \\
\hline & $\mathrm{T}_{1}$ & $\mathrm{~T}_{2}$ & $\mathrm{~T}_{1}$ & $\mathrm{~T}_{2}$ & $\mathrm{~T}_{1}$ & $\mathrm{~T}_{2}$ & $\mathrm{~T}_{1}$ & $\mathrm{~T}_{2}$ \\
\hline XL 3000 & $\begin{array}{c}0.13 \\
( \pm 0.03)\end{array}$ & $\begin{array}{c}1.50 \\
( \pm 0.23)\end{array}$ & $\begin{array}{c}0.12 \\
( \pm 0.04)\end{array}$ & $\begin{array}{c}1.38 \\
( \pm 0.18)\end{array}$ & $\begin{array}{c}0.14 \\
( \pm 0.04)\end{array}$ & $\begin{array}{l}1.32 \\
0.19\end{array}$ & $\begin{array}{c}0.14 \\
( \pm 0.03)\end{array}$ & $\begin{array}{c}1.43 \\
( \pm 0.20)\end{array}$ \\
\hline Ultraled & $\begin{array}{c}0.14 \\
( \pm 0.04)\end{array}$ & $\begin{array}{c}1.39 \\
( \pm 0.12)\end{array}$ & $\begin{array}{c}0.13 \\
( \pm 0.04)\end{array}$ & $\begin{array}{c}1.36 \\
( \pm 0.20)\end{array}$ & $\begin{array}{c}0.13 \\
( \pm 0.04)\end{array}$ & $\begin{array}{c}1.37 \\
( \pm 0.14)\end{array}$ & $\begin{array}{c}0.13 \\
( \pm 0.03)\end{array}$ & $\begin{array}{c}1.37 \\
( \pm 0.14)\end{array}$ \\
\hline
\end{tabular}

mouth, allowing the establishment of the characteristics of the restorative materials when exposed to saliva, $\mathrm{pH}$ changes and other oral influences. Thus, the in situ experiment must be considered, because the wear is a complex process that depends on the jaw movement and premature contact ${ }^{17}$, as well as, on toothbrushing ${ }^{28,29}$ and the chemical, mechanical and biological components, which can affect the bulk of the material ${ }^{24}$.

In the present study, the wear resistance was evaluated through superficial smoothness ${ }^{18}$ of materials, using roughness test and it was observed that halogen lamp and LED light-curing sources did not exhibit differences in relation to superficial roughness. A possible explanation for this fact should be that the curing sources promoted similar polymerization in the top of the specimens, because this surface is few influenced for intensity of light-curing units ${ }^{11,30,31}$. Thus, the halogen lamp did not provide lower means of roughness, although show high intensity light.

Conversely, when immediately and 30-days post-irradiation times were evaluated, it was verified an increase in the roughness means after 30-days for all tested materials. A suitable explanation for this result is the abrasion of three bodies caused for toothbrushing ${ }^{17,24,28,29,32-34}$. This wear is probably due to the fluoride toothpaste and toothbrush association action during the oral hygiene, whereas the volunteers accomplished the brushing of the appliance by three times a day.

In addition, other factors may promote the wear of the composite resins, as the centric and functional contacts, the interproximal contact areas, the attrition of the chewed food ${ }^{15,17,35,36}$ and chemical degradation of the composite resin organic matrix ${ }^{37,38}$. However, in the present study the increase on the roughness values can be due mainly to the toothbrushing procedure, because the appliances were not under occlusal stress and were removed during the ingestion of food and beverages.

Halogen lamp and LED have showed similar results in relation to roughness of restorative material, nevertheless, for that LED can be employed with security, allowing the success and the longevity of restorative treatment, news studies are needed to evaluate other characteristics of resin composites cured with LED, because it has been observed controversial results ${ }^{1,14,30,39-45}$ in relation to the restorative-materials' properties obtained when a similar light source was employed. Besides, this study assessed the roughness in a short time period. In this way, these characteristics should be evaluated after a longer time period, and using another LED unit with a high intensity density.

It is important to stand out that in situ studies, in spite of their application as predictive methods to evaluate the clinical situations, do not substitute the in vivo findings, which must be accomplished to establish with fidelity the efficacy of this light-curing unit when employed directly in oral environment.

\section{Acknowledgments}

The authors gratefully acknowledge FAPESP (Process n.2003/00498-7) and CAPES for financial support.

\section{Conclusion}

Within the limitation of an in situ study and the methodology employed, the following conclusions may be drawn:

Roughness was not influenced by light sources and by composite resins, being affected only by post-irradiation time.

\section{References}

1. Soh MS, Yap AUJ, Siow KS. Comparative depths of cure among various curing light types and methods. Operative Dentistry. 2004; 29(1):9-15.

2. Manhart J, Chen HY, Hickel R. The suitability of packable resin-based composites for posterior restorations. Journal of the American Dental Association. 2001; 132(5):639-645.

3. Mc Cabe JF, Carrick TE. Output from visible-light activation units and depth of cure of light-activated composites. Journal of Dental Research. 1989; 68(11):1534-39.

4. De Wald JP, Ferracane JL. A comparison of four modes of evaluating depth of cure of light-activated composites. Journal of Dental Research. 1987; 66(3):727-730.

5. Kim KH, Ong JL, Okuno O. The effect of filler loading and morphology on the mechanical properties of contemporary composites. The Journal of Prosthetic Dentistry. 2002; 87(6):642-649.

6. Asmussen E, Peutzfeldt A. Polymer structure of a light-cured resin composite in relation to distance from the surface. European Journal of Oral Sciences. 2003; 111(3):277-279.

7. Caldas DBM, Almeida JB, Correr-Sobrinho L, Sinhoreti MAC, Consani S. Influence of curing tip distance on resin composite Knoop hardness number, using three different light-curing units. Operative Dentistry. 2003; 28(3):315-320.

8. Harrington E, Wilson HJ, Shortall AC. Light-activated restorative materials: a method of determining effective radiation times. Journal of Oral Rehabilitation. 1996; 23(3):210-218.

9. Pires JA, Cvitko E, Denehy GE, Swift Jr EJ. Effects of curing tip distance on light intensity and composite resin microhardness. Quintessence International. 1993; 24(7):517-521.

10. Yap AUJ, Wattanapayungkul P, Chung SM. Influence of the polymerization process on composite resistence to chemical degration by foodsimulating liquids. Operative Dentistry. 2003; 28(6):723-727.

11. Soh MS, Yap AUJ, Siow KS. Effectiveness of composite cure associated with different curing modes of LED lights. Operative Dentistry. 2003a; 28(4):371-377.

12. Yearn JA. Factors affecting cure visible light activated composites. International Dental Journal. 1985; 35(3):218-225.

13. Abate PF, Zahra VN, Macchi RL. Effect of photo polymerization variables on composite hardness. Journal of Prosthetic Dentistry. 2001; 86(6):632-635.

14. Mills RW, Jandt KD, Ashworth SH. Dental composite depth of cure with halogen and blue light emitting diode technology. Brazilian Dental Journal. 1999; 186(8):338-391.

15. Lu H, Roeder LB, Lei L, Powers JM. Effect of surface roughness on stain resistance of dental resin composites. Journal of Esthetic Restorative Dentistry. 2005; 17(2):102-109. 
16. Pesun IJ, Olson AK, Hodges JS, Anderson GC. In vivo evaluation of the surface of posterior resin composite restorations: A pilot study. Journal of Prosthetic Dentistry. 2000; 84(3):353-359.

17. Chimelo DT, Palma-Dibb RG, Corona SAM, Lara EHG. Assessing wear and surface roughness of different composite resins after toothbrushing. Materials Research. 2001; 4(4):285-289.

18. Glayds S, Van Meerbeek B, Braem M, Lambrechts P, Vanherle G. Comparative physico-mechanical characterization of new hibrid restorative materials with conventional glass-ionomer and resin composite restorative materials. Journal Dental Research. 1997; 76(4):883-894.

19. Gedik R, Hurmuzlu F, Coskun A, Bektas OO, Ozdemir AK. Surface roughness of new microhybrid resin-based composites. Journal of America Dental Association. 2005; 136(8):1106-1112

20. Yap AUJ, Wang HB, Siow RS, Gan LM. Polymerization shrinkage of visible-light-cured composite. Operative Dentistry. 2000; 25(2):98-103.

21. Ten Cate JM. Patient selection and appliance design in intra-oral models. Journal of Dental Research. 1992; 71(Spec Iss-april):908-901.

22. Zero DT. In situ caries models. Advanced Dental Research. 1995; 9(3):214-230

23. Featherstone JDB, Zero DT. An in situ model for simultaneous assessment of inhibition of demineralization and enhancement of remineralization. Journal of Dental Research. 1992; 71(Spec Iss-april):804-810.

24. Turssi CP, Purquerio BM, Serra MC. Wear of dental resin composites: insights into underlying processes and assessment methods - A review. Journal of Biomedical Materials Research Part B: Applied Biomaterials. 2003; 65B(2):280-285.

25. Sarrett DC, Ray S. The effect of water on polymer matrix and composite wear. Dental Materials. 1994; 10(1):6-10.

26. Venhoven BA, De Gee AJ, Wener A, Davidson CL. Influence of filler parameters on the mechanical coherence of dental restorative resin composite. Biomaterials. 1996; 17(7):735-740.

27. Basting RT, Serra MC, Rodrigues Jr AL. In situ microhardness evaluation of glass-ionomer/composite resin hybrid materials at different post-irradiation times. 2002; Journal of Oral Rehabilitaion. 2002; 29(12):1187-1195.

28. Ehrnford L. Surface microstructure of composite resins after toothbrushdentifrice abrasion. Acta Odontol Scand. 1983; 41(4):241-245.

29. Kanter J, Koski RE, Martin D. The relationship of weight loss to surface roughness of composite resins from simulated toothbrusing. Journal of Prosthetic Dentistry. 1982; 47(5):505-513.

30. Tsai PCL, Meyers IA, Walsh JL. Depth of cure and surface microhardness of composite resin cured with blue Led curing lights. Dental Materials. 2004; 20(4):364-369.
31. St-Georges AJ, Swift Jr EJ, Thompson JY, Heymann HO. Curing light intensity effects in wear resistance of two resin composites. Operative Dentistry. 2002; 27(4):410-417.

32. Heintze SD, Forjanic M. Surface roughness of different dental materials before and after simulated toothbrushing in vitro. Operative Dentistry. 2005; 30(5):617-626.

33. Tanoue N, Matsumura H, Atsuta M. Analysis of composite type and different sources of polymerization light on in vitro toothbrush/dentifrice abrasion resistance. Journal of Dentistry. 2000; 28(5):355-359.

34. Willems G, Lambrechts P, Braem M, Celis JP, Vanherle G. A classification of dental composites according to their morphological and mechanical characteristics. Dental Materials. 1992; 8(5):310-319.

35. Lee YK, Lu H, Oguri M, Powers JM. Changes in gloss after simulated generalized wear of composite resins. Journal of Prosthetic Dental. 2005; 94(4):370-376.

36. Stahl F, Ashworth SH, Jandt KD, Mills RW. Light-emitting diode (LED) polymerization of dental composites: flexural properties and polymerization potential. Biomaterials. 2000; 21(13):1379-1385.

37. Leinfelder KF. Five-year clinical evaluation of anterior and posterior restoration of composite resin. Operative Dentistry. 1980; 5(2):57-65.

38. Sarrett DC, Coletti DP, Peluso AR. The effects of alcoholic beverages an composite wear. Dental Materials. 2000; 16(1):62-67.

39. Althoff O, Hartung M. Advances in light curing. American Journal of Dentistry. 2000; 13(Spec No):77D-81D.

40. Asmussen E, Peutzfeldt A. Light-emitting diode curing: Influence on selected properties of resin composites. Quintessence International. 2002; 34(1):71-75.

41. Besnault C, Pradelle-Plase N, Picard B, Colon P. Effect of a LED versus halogen light cure polymerization on the characteristics of three composite resins. Journal of Dentistry. 2003; 16(5):323-328.

42. Herrero AA, Yaman P, Dennison JB. Polymerization shrinkage and depth of cure of packable composites. Quintessence International. 2005; 36(1):25-31.

43. Soh MS, Yap AUJ, Siow KS. The effectiveness of cure of LED and halogen curing lights at varying cavity depths. Operative Dentistry. 2003b; 28(6):710-715.

44. Teixeira EC, Thompson JL, Piascik JR, Thompson JY. In vitro toothbrushdentifrice abrasion of two restorative composites. Journal of Esthetic Restorative Dentistry. 2005; 17(3):172-182.

45. Yoon TH, Lee YK, Lim BS, Kim CW. Degree of polymerization of resin composites by different light sources. Journal of Oral Rehabilitation. 2002; 29(12):1165-1173. 